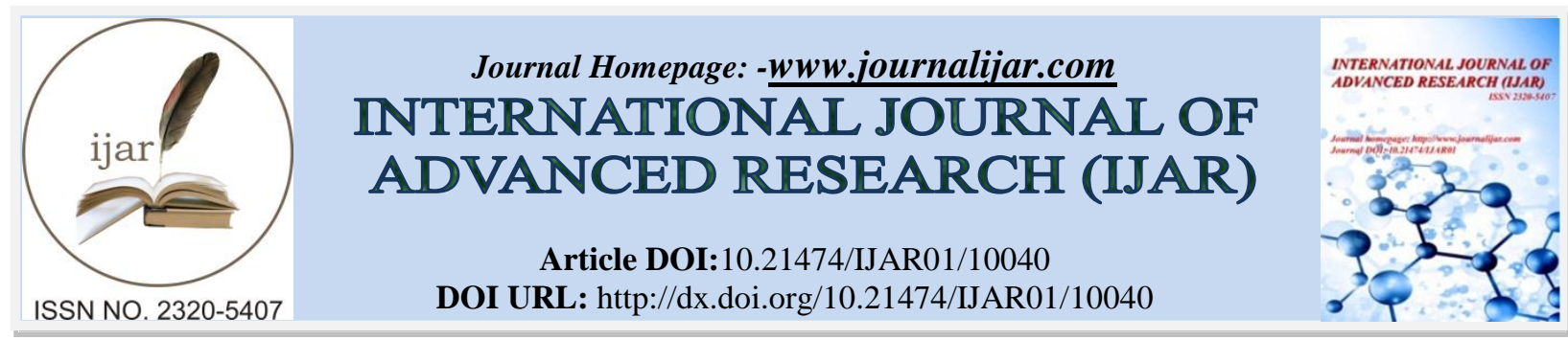

RESEARCH ARTICLE

\title{
MEASUREMENT OF RADON PERMEABILITY THROUGH DIFFERENT MEMBRANE MATERIALS BY USING SURFACE BARRIER DETECTOR (SBD) TECHNIQUE.
}

\author{
M. S. A. Khan. \\ Department of Physics, Gandhi Faiz-a-Aam College, Shahjahanpur (U.P.)-242001, India.
}

\section{Manuscript Info}

Manuscript History

Received: 10 September 2019

Final Accepted: 12 October 2019

Published: November 2019

Key words:-

Radon Permeability, SBD Detector,

Membrane Materials, Radon.

\begin{abstract}
The measurement radon permebeality through different membrane materials has been carried out by using surface barrier detector (SBD) technique. The permeability constant $\mathrm{K}$ and the relative radon permeability $\mathrm{R}=\mathrm{n}_{1} / \mathrm{n}_{2}$ for 12 different types of membrane materials (Polyethylene, Cellulose Acetate, Cellulose Nitrate, Polyvinyle Chloride-I, Polyvinyle Chloride-II, Hydrate Cellulose, Polycarbonate, Polyethylene-Terephthalate, Makrofol DE, Makrofol N, Aluminized Polycarbonate and Aluminized Mylar) have been measured. Observed results were found in good agreement with previously reported data for similar membrane materials. The permeability constant for a given commercially available materials vary considerably due to the difference in manufacturing procedures and physical properties of the same material
\end{abstract}

Copy Right, IJAR, 2019,. All rights reserved.

\section{Introduction:-}

Radon is a radioactive gas that is produced by the decay of uranium. In several studies, it has been confirmed that the inhalation of radon and its progeny is a well-known risk factor for lung cancer at uranium underground miners (Lubin et al., 1994). Radon generated radiations comes in our environment from two major sources (soil and water) by diffusion and transportation processes. The fraction of the radon which escapes depends upon the depth at which it is formed and the permeability of the ground to radon. Radon, being a gas can move from geological environment to human environment through different process; forced or diffusion and convectional flow of fluids in the earth crust. Diffusion of radon in geological and human environment can take place by Gram's law of diffusion. The diffusion of the radon gas through membranes is function of the permeability constant of the membrane materials. In general, the permeability constants for different materials are not widely available in the literature. However, published values (Abdel Fattah et al., 1986; Bigu, 1986; Giridharetal., 1982; Pohl-Ruling et. al., 1980; Ramachandran et.al., 1987; Wojcik, 1991) for a given commercially available material vary considerably due to the difference in manufacturing procedures and physical properties of the same material

In order to measure the radon gas concentration, solid state nuclear track detectors were used. It is extremely sensitive to alpha particles emitted from the two isotopes of the gas ${ }^{222} \mathrm{Rn}$ and ${ }^{220} \mathrm{Rn}$ from their decay products and from any other alpha emitters that may exist near the detector. There are few applications in which special membranes are used to separate radon $\left({ }^{222} \mathrm{Rn}\right)$ from thoron $\left({ }^{220} \mathrm{Rn}\right)$. The characteristics of these membranes is to delay the diffusion the ${ }^{222} \mathrm{Rn}$ and ${ }^{220} \mathrm{Rn}$ gas (Tanner, 1964). This results a large percentage of the long lived radon i.e. ${ }^{222} \mathrm{Rn}$ will pass through the membrane while a large percentage of the short lived radon i.e. ${ }^{220} \mathrm{Rn}$ will decay during 
its diffusion .In this paper the diffusion of radon gas $\left({ }^{222} \mathrm{Rn}\right)$ through different types of membrane has been studied using surface barrier technique. The permeability constant and the relative radon permeability for different types of materials have also been measured.

\section{Experimental Technique}

The experimental arrangement for the measurements of radon permeability is shown in the figure 1. It is a radon alpha chamber. The alpha chamber consist of two volumes $V_{1}$ and $V_{2}$ separately in which $V_{1}$ is much larger as compared to $V_{2}\left(V_{1}>>V_{2}\right)$. The volumeV $V_{1}$ is open and the second volume $V_{2}$ is separated from $V_{1}$ by a membrane material. A radon source $2.35 \times 10^{6} \mathrm{~Bq}$ of radium-226 ${ }^{226} \mathrm{Ra}$ ) was placed. The numbers of alpha counts $\mathrm{n}_{1}$ will be taken in the first volume for the measurement of radon concentration after the equilibrium have been reached and the numbers of alpha counts $\mathrm{n}_{2}$ will be taken in the second volume for the measurement of radon concentration after diffusion through the membrane. The number of alpha counts was measured after the equilibrium has been reached and it is measured in two steps. In the first steps the number of alpha counts $n_{1}$ was measured without membrane and in the second steps the number of alpha counts $\mathrm{n}_{2}$ was measured with the membrane. The method used in the present work is similar to that described by Ramachandran et al. (1987). The significant factor which determines the appropriateness of a membrane for separation radon isotopes is its permeability constant. We define a quantity $\mathrm{R}$ which is the ratio the concentrations of gaseous in volume $V_{2}$ with a membrane and the concentration without any membrane in $V_{1}$ is expressed by the following relation (Ramachandran et. al. 1987):

$$
\mathrm{R}=\mathrm{n}_{1} / \mathrm{n}_{2}=\left\{\mathrm{KA}\left(\mathrm{V}_{1}+\mathrm{V}_{2}\right)\right\} /\left\{\mathrm{KA}\left(\mathrm{V}_{1}+\mathrm{V}_{2}\right)+\mathrm{V}_{1} \mathrm{~V}_{2} \lambda \delta\right\}
$$

Where $\mathrm{K}$ is the permeability constant in $\mathrm{cm}^{2} \mathrm{~s}^{-1}, \delta$ is the thickness of the membrane in $\mathrm{cm}$, A is the surface area of the membrane in $\mathrm{cm}^{2}$ and $\lambda$ is the decay constant $\left(\mathrm{s}^{-1}\right)$. The permeability constant is given by the relation:

$$
\mathrm{K}=\left\{\mathrm{V}_{1} \mathrm{~V}_{2} \lambda \delta / \mathrm{A}\left(\mathrm{V}_{1}+\mathrm{V}_{2}\right)\right\} \times\left\{\mathrm{n}_{2} /\left(\mathrm{n}_{1}-\mathrm{n}_{2}\right)\right\}
$$

Table 1:- Observed values of radon permeability for different membrane materials

\begin{tabular}{|l|l|c|c|c|}
\hline $\begin{array}{l}\text { Short } \\
\text { Name }\end{array}$ & $\begin{array}{l}\text { Chemical name } \\
\text { of the materials }\end{array}$ & $\begin{array}{c}\text { Sample } \\
\text { Thickness } \\
\delta(\mu \mathrm{m})\end{array}$ & $\mathrm{R}=\mathrm{n}_{1} / \mathrm{n}_{2}$ & $\begin{array}{c}\text { Permeability } \\
\text { Constant } \\
\left(10^{-12} \mathrm{~m}^{2} \mathrm{~s}^{-1}\right)\end{array}$ \\
\hline PE & Polyethylene & 65 & 0.45 & 7.5 \\
\hline CA & Cellulose Acetate & 23 & 0.70 & 0.65 \\
\hline CN & Cellulose Nitrate & 15 & 0.39 & 1.9 \\
\hline PVC I & Polyvinyle Chloride & 11 & 0.73 & 0.50 \\
\hline PVC II & Polyvinyle Chloride & 10 & 0.74 & 0.63 \\
\hline HC & Hydrate Cellulose & 20 & 0.62 & 0.95 \\
\hline PC & Polycarbonate & 17 & 0.66 & 2.2 \\
\hline PET & Polyethylene-Terephthalate & 13 & 0.55 & 0.29 \\
\hline MAK_DE & Makrofol DE & 14 & 0.40 & 0.20 \\
\hline MAK_N & Makrofol N & 12 & 0.36 & 0.40 \\
\hline AP & Aluminized Polycarbonate & 35 & 0.70 & 0.35 \\
\hline AM & Aluminized Mylar & 30 & 0.60 & 0.03 \\
\hline
\end{tabular}




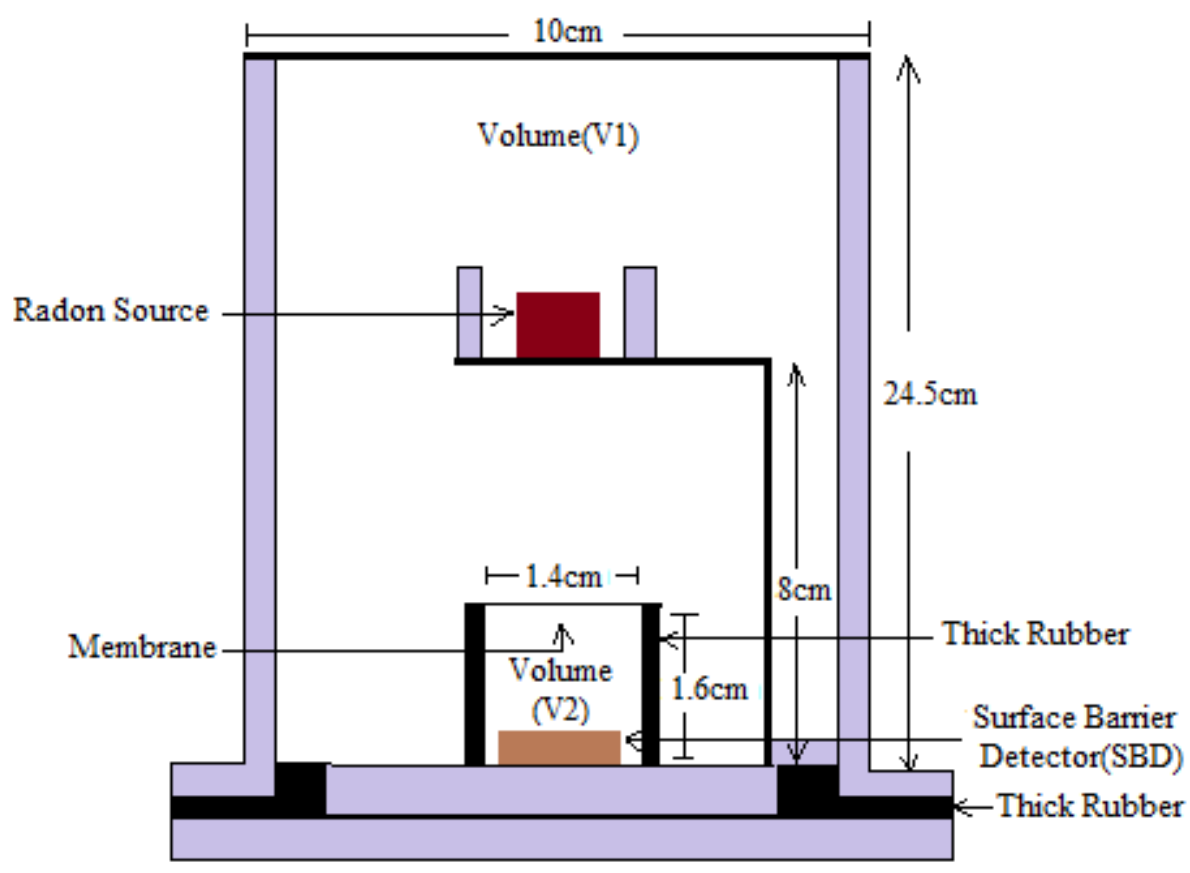

Figure1:-Schematic diagram of the radon alpha chamber.

\section{Result and Discussion:-}

The observed permeability constant for different kinds of membrane materials are given in the table 1 .These are Polyethylene, Cellulose Acetate, Cellulose Nitrate, Polyvinyle Chloride, Hydrate Cellulose, Polycarbonate, Polycarbonate-Terepthalate, Makrofol, Aluminized Polycarbonate and Aluminized Mylar. In order to obtain an average value of the permeability and ratio $n_{1} / n_{2}$, the sample were measured several times. The sample area was kept at $3 \mathrm{~cm}^{2}$ in all our measurements. The permeability constant ratio $\mathrm{n}_{1} / \mathrm{n}_{2}$ for different membrane materials was found respectively $7.5 \times 10^{-12} \mathrm{~m}^{2} \mathrm{~s}^{-1}$ and 0.45 for Polyethylene of thickness $65 \mu \mathrm{m}, 0.65 \times 10^{-12} \mathrm{~m}^{2} \mathrm{~s}^{-1}$ and 0.70 for cellulose Acetate of thickness $23 \mu \mathrm{m}, 1.9 \times 10^{-12} \mathrm{~m}^{2} \mathrm{~s}^{-1}$ and 0.39 for Cellulose Nitrate of thickness $23 \mu \mathrm{m}, 0.50 \times 10^{-12} \mathrm{~m}^{2} \mathrm{~s}^{-1}$ and 0.73 for Polyvinyle Chloride I of thickness $11 \mu \mathrm{m}, 0.63 \times 10^{-12} \mathrm{~m}^{2} \mathrm{~s}^{-1}$ and 0.74 for Polyvinyle Chloride II of thickness $10 \mu \mathrm{m}, 0.95 \times 10^{-12} \mathrm{~m}^{2} \mathrm{~s}^{-1}$ and 0.62 for Hydrate cellulose of thickness $20 \mu \mathrm{m}, 2.2 \times 10^{-12} \mathrm{~m}^{2} \mathrm{~s}^{-1}$ and 0.66 for Polycarbonate of thickness $15 \mu \mathrm{m}, 0.29 \times 10^{-12} \mathrm{~m}^{2} \mathrm{~s}^{-1}$ and 0.55 for Polyethylene-Terepthalate of thickness $13 \mu \mathrm{m}, 0$ $.20 \times 10^{-12} \mathrm{~m}^{2} \mathrm{~s}^{-1}$ and 0.40 for Makrofol DE of thickness $14 \mu \mathrm{m}, 0.40 \times 10^{-12} \mathrm{~m}^{2} \mathrm{~s}^{-1}$ and 0.36 for Makrofole $\mathrm{N}$ of thickness $12 \mu \mathrm{m}, 0.35 \times 10^{-12} \mathrm{~m}^{2} \mathrm{~s}^{-1}$ and 0.70 for Aluminized Polycarbonate of thickness $35 \mu \mathrm{m}$ and $0.03 \times 10^{-12} \mathrm{~m}^{2} \mathrm{~s}^{-1}$ and 0.60 for Aluminized Mylar of thickness 30 $\mu$ m.In our observed result an estimated error of about $18 \%$ was found. A comparison of our observed results for permeability constant and ratio $n_{1} / n_{2}$ was found good agreement than other values found in the literatures (Ramachandran et al.1987, Abdel-Fattah et. al. 1986, Giridhar et. al. 1982, Somogyi et. al.1986).

\section{Conclusions:-}

A number of membranes materials of suitable thickness have been used for the measurements of radon permeability. These membrane materials are Polyethylene, Cellulose Acetate, Cellulose Nitrate, Polyvinyle Chloride-I, Polyvinyle Chloride-II, Hydrate Cellulose, Polycarbonate, Polyethylene-Terephthalate, Makrofol DE, Makrofol N, Aluminized Polycarbonate and Aluminized Mylar. The ratio $\mathrm{R}=\mathrm{n}_{1} / \mathrm{n}_{2}$ have also been calculated which is the ratio the concentrations of gaseous in volume $\mathrm{V}_{2}$ with a membrane and the concentration without any membrane in $\mathrm{V}_{1}$. This gives the relative permeability through different membrane materials. Our observed result were found good agreement than other values found in the literatures. The permeability constant for a given commercially available materials vary considerably due to the difference in manufacturing procedures and physical properties of the same material 


\section{Acknowledgement:-}

The author is grateful to all faculty members of the concern department of the college. Special thanks to Dr. Mohammad Tariq, department of physics, M. B. P. Govt. (P.G.) College, Ashiana, Lucknow and Dr. R. B. S. Rawat, Department of physics, M. S. (P.G.) College, Saharanpur for necessary help to carry out this work.

\section{References:-}

1. Lubin, J.H., Boice, J.D., Edling, C.H., Hornung, R., Howe, G., Kunz, E., Kusiak, A., Morrison, H.I., Radford, E.P.,Samet, J.M., Tirmarche, M., Woodward, A., Xiang, Y.S. and Pierce, D.A. (1994):Radon and lung cancer risk: A joint analysis of 11 underground miners studies. US National Institutes of Health. NIH publication No. 94-3644.

2. Abdel-Fattah, H. and Somogy, G. (1986): Determination of radon and thoron permeability through some plastics by track technique. Nucl. Tracks 12: 697-700.

3. Bigu, J. (1986): An automated multisensor apparatus for comparative membrane radon and thoron permeability studied. Nucl. lnstr. and Methods A 251: 366-373.

4. Giridhar, J., Raghavayya, M., and N. Padmanabham, N. (1982): Radon permeability of some membranes. Health Phys. 42: 723-725.

5. Pohl-Ruling, J., Steinhausler, F. and Pohl, E (1980): Investigation on the suitability of various materials as ${ }^{222} \mathrm{Rn}$ diffusion barriers. Health Phys. 39: 299-301

6. Ramachandran, T.V., Lalitand, B.Y. and Mishra, U.C. (1987): Measurement of radon permeability through some membranes. Nucl. Tracks Radiat. Meas. 13: 81-84.

7. Tanner, A. B. (1964): Natural radiation environment. In: Adams, J. A. S., Lowder, W.L. Chicago: University of Chicago

8. Laot, M., Marand, E., Schmittmann, B. and Zia, R. K.P. (2003): Effects of Cooling rate and Physical aging on the Gas Transport Properties in Polycarbonate, Macromolecules, 36, 8673-8684.

9. Wojcik, M., Wlazlo, W., Zuzel, G. and Heusser., G. (2000): Radon diffusion through polymer membranes used in the solar neutrino experiment Borexino. Nucl. Instrum. Methods, B 449, 158-171.

10. claughlin, J.P.(1979): A technique for measuring the relative exhalation rates of radon and thoron from building materials. Presented at the E.E.CJS.C.P.R.I. Seminar on the Radiological Burden of Man from Natural Radioactivity in the Countries of the European Community; Vesinet, France; 4-6 December. 